Kelaniya Journal of Human Resource Management

Volume 09-Number 01-January 2014 \& Number 02-July 2014

\title{
A Review of Employee Counselling
}

\author{
M. K. D. Padmasiri ${ }^{1}$ and L. V. K. Jayathilake ${ }^{2}$ \\ ${ }^{1}$ Department of Human Resource Management, University of Kelaniya, Sri Lanka \\ ${ }^{2}$ Department of Commerce \& Financial Management, \\ University of Kelaniya, Sri Lanka \\ 1'dinithipadmasiri@kln.ac.lk, ${ }^{2}$ lakminij@kln.ac.lk
}

\begin{abstract}
Employee counselling is a Human Resource Management (HRM) practice, which uses to maintain employees' wellbeing. The objective of the present study is identify counselling techniques which can be applied in employee counselling. The literature shows that in employee counselling counselor can apply different counselling techniques including Cognitive Therapy (CT), Behavioral Therapy (BT), cognitive behavioral therapy (CBT), existentialhumanistic therapy and psychoanalysis. According to the literature, for each therapy there are different therapeutic techniques can be used. So, in Behavioral Therapy, Systematic Desensitization, Exposure Therapies, Aversion Therapy, and Biofeedback can be used. Moreover, Rational Emotive Behavior Therapy (REBT) and Reinforcement techniques can be applied as CBT techniques whilst logo therapy and gestalt therapy are using as existential-humanistic therapy techniques. Finally, in Psychoanalysis Therapy Anamnesis, Analysis / Interpretation of Dreams and Analysis / Interpretation of Symbols can be applied in employee counselling.
\end{abstract}

Keywords: Employee Counselling, CT, BT, CBT, Existential-Humanistic Therapy and, Psychoanalysis

\section{Introduction}

Employee counselling at the workplace is, discussion of an employee's problem that usually has an emotional content to it in order to help the employee cope with the situation better (Ajila, \& Adetayo, 2013). According to Gerstmanm (2014) aim of the employee counselling is to assist both the employer and employee by intervening with an active problem-solving approach to tackling the problems at hand. Further he stated specific aims of employee counselling, those are, explore and find the key sources of difficulty, review the individual's current strategies and styles of coping, 
implement methods of dealing with the perceived problem, thereby alleviating the issue and evaluate the effectiveness of chosen strategies. Pickerell (2011) has revealed that counselors can help individuals to find and maintain work that uses their skills, talents, and attributes in order to support career engagement. Further he revealed that counselors can also advocate for lifelong career management by keeping challenge and capacity in a reasonable balance through taking on special projects or new positions to stay challenged, engaging in continuing education, or developing an effective support system. Similarly, counselors can help employers support career engagement through special projects; cross training; transferring employees into different positions; or, in some cases, facilitating a gracious exit from the organization. Use of this model, both counselors and employers can support individuals to make the necessary career adjustments to stay fully engaged. In the words of Stone (2007), there is a process for performance counselling to boost employee performance.

\section{Early Theoretical Findings}

Being in lines with the previous literature, the following sections precisely discuses about the employee counselling and counselling techniques which can be applied in the counselling sessions.

\subsection{Employee Counselling}

In some cases employee counselling operate as Employee Assistant Programme (EAP) and as pointed by King (1994), EAP takes three forms: in house organizational counselling: within the organization premises do counselling, discrete contracts with external agencies; external agency do counselling for internal employees, and a 24 hour telephone link for personal counselling: based on individual employee requirement. Most of the organizations are practicing above three forms in order to maintain employee mental happiness.

According to Carroll (1995), counselors in the organization sometime called as welfare officers and organizations believe counselors are doing miraclecure for all disciplinary procedure, personal hygiene, and mental illnesses. In the same study has discussed that, good employee counselor is playing varied role with clients, maintain good communication with managers, conducting 
training courses, and occasionally visit employees' homes. Therefore, employee counselling is not a simple mission and employee counselors are holding responsible role within the organization.

Orlans (1992) has defined the task of counselor as, "build the bridge between different worlds" and those two worlds are the world of counselling and the world of organization. Hence, counselor works as a mediator between employer and employee to create cohesive work environment. Counselor's job is one of the most difficult job hence it deals with ever changing human mind. Organizational counselor is not only a counselor but also trainer, consultant, organizational agent of change, counselling manager, informant, advocate, advice giver, diplomat, and hopefully human (Carroll, 1995).

Benefits of employee counselling listed by Mintz (2014), those are helping individual employee to understand their issue and situation clearly, helping to make decisions and alternative solutions to issues, and to coping with the situation and the stress. In the conclusion of above discussion it can be identified that employee counselling is important to any organization.

\section{Counselling Techniques}

There are various counselling techniques in the field of counselling which support to conduct productive counselling session. Counselling technique that commonly use are, cognitive therapy, behavioral therapy, existential therapy, psychoanalysis, and humanistic therapy, and holistic therapy (American Psychology Association, 2016). In the following discussion, clearly defines counselling therapies, which are using in counselling.

\subsection{Cognitive Therapy}

Cognitive Therapy (CT) is one of the most important psychotherapy techniques using to change human mind and validated in hundreds of cognitive psychology studies (Beck, 2010). CT is a system of psychotherapy that attempts to modify their dysfunctional behavior, and corrected the distortions in their thinking, they quickly experienced enduring improvement in their mood, symptoms, functioning, and relationships (Beck, Rush, Shaw, \& Emery, 1979). CT focuses not only on their most superficial level of thinking (their automatic thoughts), but also on deeper level cognitions (their 
basic assumptions and core beliefs) and patterns of dysfunctional behavior (Beck, 2009).

This therapy invented by Aron Beck in 1960s' and developed based on specific cognitive conceptualization of the individual. According to Beck (2010), CT is goal oriented, time focused, educative and collaborative approach, which initially conduct intensive evaluation to diagnose clients by review of client aspect of the client's history, therapist help to conceptualize and understand how client is thinking has influenced his/ her emotions and ultimately change the thinking of client on particular event. In the same study highlighted that therapist counsel clients; to solve their issue, to test their thinking themselves, to develop new core beliefs, to alter maladaptive behavior by changing the way thinking, to improve relationship and to regulate emotions by themselves. At the very first CT developed for depression subsequently, apply to develop cognitive formulations and treatments for other disorders as well. Result of that, has found CT is known to be effective in the treatment of medical conditions such as insomnia, infertility, fibromyalgia, chronic pain, irritable bowel syndrome, erectile dysfunction, obesity, premenstrual syndrome, and migraine headaches (Beck, 2010).

\subsection{Behavioral Therapy}

In 1900s, John B. Watson introduced behaviorism theory who was the father of behaviorism and, Behavioral Therapy (BT) grounded on the theory of behaviorism (Hayes, 2004). However, it established as a psychological approach in 1950s and 1960s. Simply through this therapy, attempt to change the behavior of client and it has verified in the study of Hayes (2004) since he has stated that BT focus directly on problematic behavior and emotion, to change behavior. BT based studies observe behavior rather than mental process as in cognitive therapy. BT has been introduced Acceptance and Commitment Therapy (ACT); removal of a client's problematic behaviors from the contexts that participate in that event (merely analyzing manifested behavioral symptoms themselves) (Hayes, 2004).

There are a number of treatments used in behavioral therapy that have been scientifically validated as being successful approaches to treating symptoms. Literature on behavioral therapy shows different techniques that can be 
applied such as, Systematic Desensitization (Weiten, 2007), Exposure Therapies (Corey, 2005), Aversion Therapy (Weiten, 2007), and Biofeedback (Weiten, 2007).

Systematic Desensitization was developed by Joseph Wolfe and was designed for clients with phobias. This treatment follows a process of "counterconditioning" meaning the association between the stimulus and the anxiety is weakened (Weiten, 2007). Exposure Therapies designed to expose the client to feared situations similar to that of systematic desensitization (Corey, 2005). The therapies included are in vivo desensitization and flooding. In vivo desensitization involves the client being exposed to real life anxiety provoking situations. The exposure is brief to begin with and eventually the client is exposed for longer periods to the fearful situation. As with systematic desensitization, the client is taught relaxation techniques to cope with the anxiety produced by the situation. Flooding involves the client being exposed to the actual or imagined fearful situation for a prolonged period of time. Aversion Therapy is the most controversial of the behavioral treatments and is used by therapists as a last resort to an aversive behavior (Weiten, 2007). This treatment involves pairing the aversive behavior (such as drinking alcohol) with a stimulus with an undesirable response (such as a medication that induces vomiting when taken with alcohol). Biofeedback involves the therapist getting feedback of the client's bodily functions and in turn providing the information to clients to help him or her engage in relaxation techniques (Weiten, 2007).

\subsection{Cognitive Behavioral Therapy (CBT)}

To change the behavior of the client therapist must deal with feelings and thoughts in a more direct and central way. Accordingly, psychologist has introduced CBT. Among forms of psychotherapy, CBT has been taken important role, which is highly effective for adult unipolar depression, adolescent unipolar depression, generalized anxiety disorder, panic disorder with or without agoraphobia, social phobia, Post-Traumatic Stress Disorder (PTSD), and childhood depressive and anxiety disorders (Andrew \& Butler, 2006). CBT focuses on changing both cognitive and behavior to rescue client. Simply CBT is a combination of the basic therapies; CT and BT (Beck, 2011). As pointed out by Andrew and Butler (2006) there is a growing trend of using 
CBT for mental disorders and problems hence, applying CBT will produce effective results. Distinct feature of CBT is the proposition that symptoms and dysfunctional behaviors often cognitively mediated. As per Pucci (2006) individuals improvement can be produced by modifying dysfunctional thinking and beliefs.

Rational Emotive Behavior Therapy (REBT) and Reinforcement introduce as techniques of CBT (David, 2014; Pucci, 2006). Further David (2014) has revealed that REBT uses when people become emotionally distressed due to irrational believes and that the counsellor should convince the client that he /she should replace those believes with rational believes. Reinforcement helps the client to counteract negative cognitive biases, and develop more balanced view of herself/himself about the world, and the future, restore activity levels; especially those give sense of pleasure or achievement and increase active engagement and problem solving (Pucci, 2006). Further, he has described that CBT is a collaborative approach hence client and counsellor both have to involve to get successful outcomes. Accordingly, client plays a role by defining goals, expressing concerns, learning $\&$ implementing learning whilst therapist plays a role by helping to the client for defining goals, listening, teaching, encouraging. Further, the literature has claimed that modifying dysfunctional thinking and, modifying irrational believe and behavior (REBT) result to reduced employee turnover (Proudfoot, et al., 2009).

\subsection{Existential - Humanistic Therapy}

Based on Existential-Humanistic Theory, Existential-Humanistic Therapy EHT), provides a rich, comprehensive, and practical overview since 1978s (Krug, 2010). Main purpose of using this therapy is remove mental problems and disorders by directly making sense of human existence. Techniques, which are using in EHT are, logo therapy (Melton \& Schulenberg, 2008), and gestalt therapy: emphasis on individual responsibility (Center for Substance Abuse Treatment, 1999).

Logo therapy is the main therapy describes in existential psychology. It explains the process of bringing client in to the reality in order to make selfunderstanding on real life. EHT promotes self-awareness and personal growth by stressing current reality, analyzing and altering specific patterns of response (Bugental, 1978). Gestalt therapy is an experiential and humanistic approach; it works with patients' awareness and awareness skills rather than 
using the classic psychoanalytic reliance on the analyst's interpretation of the unconscious. Also, in gestalt therapy the therapist is actively and personally engaged with the patient, rather than fostering transference by remaining in the analytic role of neutrality (Yontef \& Jacobs, 1989). In addition, the literature has revealed that Logo therapy supposed to build a meaningfulness of work in order to gain employee engagement and commitment (Morrison, Burke \& Greene, 2007).

\subsection{Psychoanalysis}

Psychoanalysis was found by Sigmund Freud (1856-1939) and hence father of this theory is Sigmund Freud. Freud believed that people could be cured by making conscious their unconscious thoughts and motivations, thus gaining insight. The aim of psychoanalysis therapy is to release repressed emotions and experiences, i.e. make the unconscious conscious (McLeod, 2007).

Psychoanalysis is not a strange therapeutic technique and (Swarte, 1998). In Swarte's (1998) study linked psychoanalysis theory with the management field and elaborated that management tries to get efficiency and on the other hand, psychoanalysis tries to get efficiency in personal and professional life. Above findings supposed to verify the significance of psychoanalysis to solve issue at organizational level and in order to capture organizational success.

Further, as revealed in the site of Sigmund Freud Page (2002), psychoanalysis techniques are; Anamnesis: the interpretation of the biographic (personal) events during the psychoanalytical cure may settle the neurotic frame of the individual's psychopathology, Free Associations Method: this consists in gathering the free associations provided by the patient during the cure, Analysis/Interpretation of Dreams: dream interpretation is considered by him an irreplaceable means to access the unconscious, and Analysis/Interpretation of Symbols: symbols occur in dreams, fantasies, fairy tales and other such psychical and cultural products, and they may be interpreted in the same way as dreams.

According to Swarte (1998), even though Psychoanalysis therapy and management are two concepts, psychoanalysis can be applied to manage human behavior in organizations. Further, Wachtel (1997) revealed that 
psychoanalysis therapy can be used with behavioral therapy, which helps to behavioral changes of employees.

\section{Discussion}

According to the current literature, there are different techniques in Behavioral Therapy including Systematic Desensitization (Weiten, 2007), Exposure Therapies (Corey, 2005), Aversion Therapy (Weiten, 2007), and Biofeedback (Weiten, 2007). The literature (Weiten, 2007; Corey, 2005) on above therapeutic methods showed that those therapies change the behavior of people accordingly, the present study identifies that using above therapies at the counselling process can be changed the behavior of employees.

Moreover, CBT related literature supposed to verify that Rational Emotive Behavior Therapy (REBT), and Reinforcement introduce as techniques of CBT (David, 2014; Pucci, 2006) are techniques which can be applied as CBT at the counselling. Further, literature shows (David, 2014; Pucci, 2006) that use of Rational Emotive Behavior Therapy (REBT), and Reinforcement affected to change the behavior of people at the counselling process. It implies that CBT affected on employee behavior, accordingly the present study attempts to find the impact of counselling on employee retention. Furthermore, Proudfoot et al. (2009) verified that modifying irrational believe and behavior (REBT) in CBT result to reduced employee turnover. Therefore, the present study recognizes that CBT can be applied as counselling technique.

Techniques, which identified in existential-humanistic therapy was, logo therapy (Melton \& Schulenberg, 2008), and gestalt therapy: emphasis on individual responsibility (Center for Substance Abuse Treatment, 1999). Literature has revealed that Logo therapy supposed to build a meaningfulness of work in order to gain employee engagement and commitment (Morrison et al., 2007). Therefore, the present study intends to apply logo therapy as counselling technique in existential-humanistic therapy and in order to gain employee engagement and commitment even at the exit interview time. Thereby, the researcher attempts to retain employee moreover in the organization. Moreover, Martin et al. (2011) revealed that purpose in life might motivate behavior change by means of perceived discrepancy of values and goals with behavior. Existential- Humanistic therapy supposed to build a purpose for life (Krug, 2010) accordingly, this study identified that 
Existential- Humanistic therapy supposed to change the human behavior. Therefore, employee counselors can apply Existential- Humanistic therapy to change the behavior of people while building a purpose for life.

The literature shows various techniques in Psychoanalysis Therapy as, Anamnesis: the interpretation of the biographic events and settle the issue, Free Associations Method: freely associate with the client, Analysis/Interpretation of Dreams: dream interpretation, and Analysis/Interpretation of Symbols: symbols occur in dreams (Sigmund Freud Page, 2002). As per Swarte (1998), psychoanalysis can be applied to manage human behavior in organizations. Therefore, the present study identifies that counseling can be applied to change the behavior of employees.

\section{Conclusion}

The main objective of the present study was identify counselling techniques in order to recommend them for employee counselling. The available literature showed that counselling could be used to change the human behavior accordingly counselors or Human Resource Management practitioners can apply different counselling technique in employee counselling to change the human behavior and to improve employees' wellbeing. The literature suggested to use cognitive therapy, behavioral therapy, CBT, existential-humanistic therapy and psychoanalysis in counselling. Thus, the present study recommend to practice above counselling techniques in employee counselling.

\section{References}

Ajila, C. O., \& Adetayo, H. O. (2013, Nov 1). Workplace Counselling: Implications for Enhanced Productivity. IFE Psychologia, 21(3), 197210.

Andrew C. Butler a, J. E. (2006). The empirical status of cognitivebehavioral therapy:A review of meta-analyses. Clinical Psychology Review, 17-31.

Beck, J. S. (2011). Cognitive behavior therapy: Basics and beyond (2nd ed.). New York: NY: The Guilford Press.

Beck, A. T. (1964). Thinking and depression: Theory and therapy. Archives of General Psychiatry, 10(1), 561-571. 
Beck, A. T., Rush, A. J., Shaw, B. F., \& Emery, G. (1979). Cognitive therapy of depression. New York: Guilford Press.

Beck, J. S. (1995). Cognitive therapy: Basics and beyond. New York: Guilford Press.

Beck, J. S. (2009). The Corsini Encyclopedia of Psychology. (I. B. Weiner, \& W. E. Craighead, Eds.) John Wiley \& Sons, Inc.

Beck, J. S. (2010, Jan 30). Cognitive Therapy. Beck Institute for Cognitive Therapy and Research and University of Pennsylvania.

Bugental, J. (1978). Psychotherapy and Process: The fundamentals of an existential-humanistic approach. Menlo Park: CA: Addison-Wesley.

Carroll, M. (1995). The counsellor in organizational settings some reflections. Employee Councelling Today, 7(1), 23-29.

Center for Substance Abuse Treatment. (1999). Chapter 6 --Brief Humanistic and Existential Therapies. In R. (. Administration, Treatment Improvement Protocol (TIP) Series. US.

Corey, C. (2005). Theory and practice of counseling \& psychotherapy (7th ed.). Belmont: CA: Thomson Learning.

David, D. (2014). Rational Emotive Behavior Therapy in the Context of Modern Psychological Research. New York: Albert Ellis Institute.

Denzin, K. N., \& Lincoln, S. Y. (2003). Introduction: The Discipline and Practice of Qualitative Research. In Y. S. K. Denzin (Ed.), Qualitative Research (pp. 1-32). Thousands Oaks: CA; Sage.

Gerstmanm, P. (2014). pgagroup. Retrieved from PGA Group: www.pgagroup.com/employee-counseling

Hayes, S. C. (2004). Acceptance and Commitment Therapy,Relational Frame Theory, and the Third Wave of Behavioral and Cognitive Therapies. Behavioural Therapy, 639-665.

King, S. (1994). Counselling through Employee Assistance Programmes. Management Development Review, 07.

Krug, K. J. (2010). Existential-Humanistic Therapy. Washington: American Psychological Association. 
Martin, R. A., MacKinnon, S., Johnson, J., \& Rohsenow, D. J. (2011, Sep

1). Purpose in Life Predicts Treatment Outcome Among Adult Cocaine Abusers in Treatment. 40(2), 18-188.

McLeod, S. (2007). Psychoanalysis. Retrieved August 08, 2016, from simplypsychology.org:

http://www.simplypsychology.org/psychoanalysis.html

Melton, A. M., \& Schulenberg, S. E. (2008). On the Measurement of Meaning: Logotherapy's Empirical Contributions to Humanistic Psychology. The Humanistic Psychologist, 36(1), 31-44.

Mintz. (2014, 08 14). Benefits of Workplace Counseling. Retrieved 02 19, 2016, from workplace ethics advice:

http://www.workplaceethicsadvice.com/2014/08/benefits-ofworkplace-counseling.html

Morrison, E. E., Burke, G. C., \& Greene, L. (2007). Meaning in Motivation: Does Your Organization Need an Inner Life? Faculty PublicationsSchool of Health Administration, Texas State University.

Orlans, V. (1992). Counselling in the workplace. Part 1 - Counsellor perspectives and training, 01(01), 19-21.

Pickerell, R. A. (2011). career engagement: bridging career . journal of employment counseling, 185-189.

Proudfoot, J. G., Corr , P. J., \& Davi, G. (2009). Cognitive-behavioural training to change attributional style improves employee well-being, job satisfaction, productivity, and turnover. Perosnality and Individual Differences, 46(1), 147-153.

Pucci, A. R. (2006). The client's guide to cognitive-behavioral therapy: how to live a healthy, happy life-- no matter what (Vol. 02). New York: iUniverse.

Sigmund Freud Page. (2002). Introduction to the Psychoanalytic Techniques. Retrieved August 08, 2016, from Sigmund Freud - Life and Work: http://www.freudfile.org/

Stone, M. F. (2007). Coaching, counseling and mentroing: How to Choose \& Use the Right Technique to boost employee performance. 
Kelaniya Journal of Human Resource Management

Volume 09-Number 01-January 2014 \& Number 02-July 2014

Swarte, T. d. (1998). Psychoanalysis and management: the strange meeting of two concepts. Journal of Managerial Psychology, 13(07), 459-468.

Weiten, W. (2007). Psychology: Themes \& Variations. (7 th ed.). Pacific Grove: CA: Thomson.

Yontef , G., \& Jacobs , L. (1989). Gestalt Therapy. In D. W. Raymond J. Corsini, Current Psychotherapies (Vol. 9th ). USA. 